\title{
LA RESPONSABILIDAD DEL ARRENDADOR DERIVADA DE DAÑOS AMBIENTALES INDIRECTOS OCASIONADOS POR EL ARRENDATARIO EN ARGENTINA*
}

\author{
THE RESPONSIBILITY OF THE \\ LESSOR DERIVED FROM INDIRECT \\ ENVIRONMENTAL DAMAGES CAUSED \\ BY THE LESSEE IN ARGENTINA
}

\author{
Haraví Eloisa Ruiz*** \\ Guillermo Gapel-Redcozub***
}

Fecha de recepción: 2 de febrero de 2016

Fecha de aceptación: 8 de marzo de 2016 Disponible en linea: 30 de noviembre de 2016

\section{Para citar este artículo/To cite this article}

\begin{abstract}
Ruiz, Haraví Eloisa \& Gapel-Redcozub, Guillermo, La responsabilidad del arrendador derivada de daños ambientales indirectos ocasionados por el arrendatario en Argentina, 133 Vniversitas, 271-300 (2016). http://dx.doi. org/10.11144/Javeriana.vj133.radd
\end{abstract}

doi: 10.11144/Javeriana.vj133.radd

* Artículo de investigación.

** Abogada, Facultad de Derecho y Ciencias Sociales, Universidad Nacional del Nordeste, UNNE, Argentina. Especialista en docencia universitaria, Facultad de Humanidades, UNNE. Especialista en teoría y técnica del proceso judicial, Facultad de Derecho y Ciencias Sociales, UNNE. Miembro de las cátedras de derecho agrario y ambiental, Facultad de Derecho y Ciencias Sociales, UNNE y de Instituciones del Derecho Privado II, Facultad de Ciencias Económicas, UNNE. Becaria doctoral Conicet. Contacto: haraviruiz@gmail.com

*** Abogado, Facultad de Derecho y Ciencias Sociales, Universidad Nacional del Nordeste, UNNE, Argentina. Licenciado en economía, Facultad de Ciencias Económicas. UNNE. Especialista en docencia universitaria, Facultad de Humanidades, UNNE. Master of Laws, Harvard Law School. Profesor titular regular de derechos reales, Facultad de Derecho y Ciencias Sociales, UNNE. Contacto: guillermogapel@gmail.com 


\section{RESUMEN}

Las transformaciones productivas ocurridas en las últimas décadas en el sector agropecuario argentino han impulsado una división entre la titularidad de la tierra y su explotación. Este desdoblamiento se instrumenta habitualmente mediante contratos de arrendamiento en los que los dueños transfieren el uso y goce del recurso a nuevas formas de organizaciones empresariales (pools de siembra). En un contexto en el que comienzan a multiplicarse los conflictos ambientales asociados a explotaciones rurales insustentables, el presente trabajo lleva adelante una investigación que tiene por objetivo reinterpretar los derechos y obligaciones de las partes del contrato de arrendamiento, con un enfoque particular en los deberes ambientales del arrendador. Con base en el bloque normativo integrado por la Constitución Nacional, la Ley General del Ambiente y el Código Civil y Comercial, concluimos que el arrendador está sometido a un verdadero deber de control sobre las actividades que se desarrollan sobre su propiedad, y que en caso de incumplimiento de este deber y frente a daños ambientales indirectos, podrá ser tenido por responsable y obligado a costear las reparaciones correspondientes.

Palabras clave: Contrato de arrendamiento rural; responsabilidad ambiental; daños ambientales; explotación agrícola; pools de siembraArgentina. 


\section{ABSTRACT}

During the last decades there were huge changes in the Argentinean farming sector, among which stands out the fact that the new business model (known as sowing pools) do not rely on buying the land, but on leasing it. As a consequence farmland leases spread all over the country while environmental conflicts related to unsustainable farming practices escalates. In this context we review the lessor environmental duties under the National Constitution, the Environment General Act, the new Civil and Commercial Code and the Farm Lease Act. We conclude that the lessor is obliged to supervise that the lessee won't undertake unsustainable activities, and therefore can be held responsible if he fails to perform his duties and third parties are damaged.

Keywords: rural lease contract; environmental responsibility; environmental damages; rural development; sowing pools- Argentina

\section{SUMARIO}

Introducción.- I. El CONTRATO de ARRENDAMIENTO RURAL en ARgENTINA. SuS RASGOS DESTACADOS.- II. DAÑO AMBIENTAL: CONCEPTO, CLASES Y REGÍMENES DE RESPONSABILIDAD.- III. LAS PAUTAS DE INTERPRETACIÓN EN EL CÓDIGO Civil y COMERCIAL de LA NACIÓN.- IV. REINTERPRETACIÓN DE LA PROHIBICIÓN DE EXPLOTACIÓN IRRACIONAL (ART. 8 DE LA LAR).- V. Síntesis.- BibliogRAfía. 


\section{INTRODUCCIÓN}

Las investigaciones sobre desarrollo rural coinciden en remarcar que la estructura productiva agropecuaria argentina ha experimentado notables modificaciones en las últimas décadas. CARLA GRAS explica que a partir de los años 90 se ha consolidado un paradigma que denomina "agronegocio". Este modelo combina la lógica de expansión agroindustrial propia del siglo XX (caracterizada por la subordinación del sector agrario al sector industrial) con los nuevos rasgos de la agricultura globalizada, entre los que se destacan la incorporación de nuevas formas de tenencia de la tierra y de organización de la producción, notables innovaciones tecnológicas en los insumos, mayor concentración y transnacionalización de la propiedad de la tierra y de las redes de proveedores y comercializadoras, y la primacía de la lógica de mercado en el diseño de las políticas públicas en la materia ${ }^{2}$.

Para RoBerto BisAng, tras un "proceso evolutivo de varias décadas", el sector agropecuario argentino ha adoptado un esquema de producción en el que "los operadores de la tierra son distintos a los propietarios, la tecnología es crecientemente provista por empresas industriales y/o de servicios, los servicios y la industria forman parte ineludible del proceso $\mathrm{y}$, crecientemente, los contratos verbales $\mathrm{y} / \mathrm{o}$ escritos son la base del mecanismo de relacionamiento intrasectorial. [...] se han ido generando nuevos perfiles empresarios, formas

1 Carla Gras, Los empresarios de la soja: cambios y continuidades en la fisonomía y composición interna de las empresas agropecuarias, 12 Mundo Agrario, 24 (2012). Disponible en: http:// mundoagrario.unlp.edu.ar/article/view/v12n24a04/2142

2 En igual sentido, Carla Gras \& Valeria Hernández, coords., La Argentina rural. De la agricultura familiar a los agronegocios (Biblos, Buenos Aires, 2009). CARLA Gras \& VAleria Hernández, coords., El agro como negocio. Producción, sociedad y territorios en la globalización (Biblos, Buenos Aires, 2013). Miguel Teubal, Globalización y expansión agroindustrial. ¿Superación de la pobreza en América Latina? (Corregidor, Buenos Aires, 1995). Miguel Teubal \& Jorge Rodríguez, Agro y alimentos en la globalización: una perspectiva crítica (La Colmena, Buenos Aires, 2002). Edith Scheinkerman de Obschatko, El aporte del sector agroalimentario al crecimiento económico argentino 1965-2000 (Instituto Interamericano de Cooperación para la Agricultura, IICA, Buenos Aires, 2003). Disponible en: http://www.sidalc. net/repdoc/A8548e/A8548e.pdf. Sobre una visión latinoamericana del fenómeno: Fernando Soto-Baquero \& Sergio Gómez, eds., Dinámicas del mercado de la tierra en América Latina y el Caribe: concentración y extranjerización (Organización de las Naciones Unidas para la Alimentación y la Agricultura, FAO, Roma, 2012). Disponible en: www.fao.org/docrep/019/ i2547s/i2547s.pdf 
de financiamiento, articulaciones con la industria y los servicios (aguas arriba y aguas abajo), e incluso, instituciones"3.

Las nuevas organizaciones empresariales cumplen un rol preponderante en este escenario, al coordinar y asegurar la provisión de los distintos recursos necesarios para la producción (tierra, maquinarias, insumos, capital y recursos humanos). Francisco Díaz-Hermelo y Alejandro Reca las denominan "asociaciones productivas" $\mathrm{y}$, por lo general, se conocen como "pools de siembra"5. Roberto Bisang, Guillermo Anlló y Mercedes CAmpi se refieren a estos actores económicos como "Empresas de Producción Agropecuaria" (EPA) y afirman que pueden adoptar variadas formas jurídicas, desde sociedades de hecho - en emprendimientos de pequeña escala-, hasta sociedades comerciales, pasando por uniones transitorias de empresas y diversas clases de fideicomisos ${ }^{6}$. Uno de los objetivos esenciales de estas asociaciones productivas es el de hacerse con las tierras para llevar adelante la explotación, recurso que consiguen generalmente mediante la constitución de contratos de arrendamiento con los propietarios ${ }^{7}$. De esta manera,

3 Roвerto BisAng, El desarrollo agropecuario en las últimas décadas: „volver a creer?, en Crisis, recuperación y nuevos dilemas: la economía argentina 2002-2007, 187-260, 242 (BERNARDO P. KosaCoff, ed., Comisión Económica para América Latina y el Caribe, CEPAL, Buenos Aires, 2007). Disponible en: http://repositorio.cepal.org/handle/11362/4237, http://repositorio.cepal. org/bitstream/handle/11362/28481/1/S2007021_es.pdf

4 "Son aquellos grupos que organizan su esquema de producción reuniendo individuos, o empresas, que aportan los distintos recursos (tierra, maquinaria, insumos, capital) y capacidades (gestión técnica y gerenciamiento administrativo) necesarios para la producción agrícola. Los aportes se realizan bajo variadas estructuras de participación, conllevando distintos riesgos y retornos". Francisco Díaz-Hermelo \& Alejandro Reca, Capítulo 9, Asociaciones Productivas (APS) en la Agricultura: una respuesta dinámica a fallas de mercado y al cambio tecnológico, en El crecimiento de la agricultura argentina. Medio siglo de logros y desafios, 207-230, 207 (Lucio G. Reca, Daniel Lema \& Carlos Flood, eds., Editorial Facultad Agronomía de la Universidad de Buenos Aires, UBA, Buenos Aires, 2010).

5 Sobre el concepto y clases de pools de siembra: Susana Grosso, María Eva Bellini, Laura Qüesta, Martine Guibert, Silvia Lauxmann \& Fabiana Rotondi, Impactos de los "pools de siembra" en la estructura social agraria: Una aproximación a las transformaciones en los espacios centrales de la provincia de Santa Fe (Argentina), 6 Revista de Estudios Regionales y Mercado de Trabajo, 115-138 (2010). Disponible en: http://www.memoria.fahce.unlp.edu.ar/ art_revistas/pr.4537/pr.4537.pdf

6 Roberto Bisang, Guillermo Anlló \& Mercedes Campi, Capitulo 10, Organización del agro. La transición de un modelo de integración vertical a las redes de producción agrícola, en El crecimiento de la agricultura argentina. Medio siglo de logros y desafíos, 231-254, 242 (Lucio G. Reca, Daniel Lema \& Carlos Flood, eds., Editorial Facultad Agronomía de la Universidad de Buenos Aires, UBA, Buenos Aires, 2010).

7 Los dueños de la tierra transfieren la explotación del recurso por múltiples motivos: son herederos de la tierra sin vocación productiva; carecen de capacidad técnica, comercial o administrativa; no cuentan con suficiente financiamiento; tienen problemas de escala o han sido gravemente afectados por eventos climáticos adversos. Francisco Díaz-Hermelo \& Alejandro 
evitan la inmovilización de grandes capitales (que tradicionalmente se destinaban a la adquisición del dominio de las tierras rurales), lo que optimiza la rentabilidad del emprendimiento ${ }^{8}$.

La utilidad que han brindado estos contratos es descripta por Osvaldo BARSKy y JoRge Gelman, quienes sostienen:

la intensificación productiva de las unidades agropecuarias sobre la base de un uso más intensivo del capital y las características propias de un manejo empresarial cada vez más complejo, dieron como resultado un importante proceso de concentración de la producción en unidades de mayor tamaño (...) Por cierto que el mejor indicador para medir estos cambios no es el de la concentración de la propiedad. Diversas formas de cesión de la tierra, a través de contratos accidentales, los arriendos y otras formas de acceso facilitaron a los diversos poseedores de capital producir en unidades de mayor tamaño, fortaleciendo así un control de los procesos productivos (... $)^{9}$.

\section{De acuerdo al Censo Nacional Agropecuario de $2002^{10}$, unas} 20 millones de hectáreas están bajo el régimen de arrendamiento, y más de la mitad de esta superficie arrendada se concentra en las provincias con mayores potencialidades productivas (Buenos Aires, Santa Fe y Córdoba) ${ }^{11}$.

Paralelamente a estas transformaciones productivas, se ha verificado una serie significativa de conflictos ambientales que incluyen graves daños sufridos por personas, animales y el ambiente ${ }^{12}$, aso-

Reca, Capítulo 9, Asociaciones Productivas (APS) en la Agricultura: una respuesta dinámica a fallas de mercado y al cambio tecnológico, en El crecimiento de la agricultura argentina. Medio siglo de logros y desafíos, 207-230, 210-211 (Lucio G. ReCA, Daniel Lema \& CARlos Flood, eds., Editorial Facultad Agronomía de la Universidad de Buenos Aires, UBA, Buenos Aires, 2010).

8 Una lista de las ventajas comparativas provistas por este modelo puede hallarse en: EDUARDO Manciana, Mario Trucco \& Martín PiñeIro, Large-Scale Acquisition of Land Rights for Agricultural or Natural Resource-Based Use: Argentina, 1-84 (World Bank, Working Paper, 2009). Disponible en: http://papers.ssrn.com/sol3/papers.cfm?abstract_id=1915343. La perspectiva empresaria, narrada por un referente del sector, puede encontrarse en: GUSTAVO GROBOCOPATEL, Los agronegocios y la sustentabilidad en la economía del conocimiento, Suplemento Ambiental Revista La Ley (29 de abril de 2013). Disponible en: http://www.losgrobo.com.ar/comunicados/ descargas/suplemento_agro29042013.pdf

9 Osvaldo Barsky \& Jorge Gelman, Historia del agro argentino. Desde la Conquista hasta fines del siglo $X X, 467$ ( $3^{\text {a }}$ edición actualizada, Sudamericana, Buenos Aires, 2009).

10 Aunque formalmente se realizó un censo agropecuario en 2008, sus resultados han sido severamente cuestionados por sufrir inconsistencias metodológicas.

11 Argentina, Instituto Nacional de Estadísticas y Censos, INDEC, Censo Nacional Agropecuario 2002. Disponible en: http://www.indec.mecon.gov.ar/agropecuario/cna_defini2.asp

12 Silvina Heguy, Mal uso y falta de control: el drama de los chicos que crecen en pueblos fumigados, Diario Clarín, 6 de enero de 2013. Disponible en: http://www.clarin.com/zona/Mal-uso-faltacontrol_0_842315859.html. CARMEN Verlichak, El agua sube turbia en Junín, Diario La Nación, 19 de marzo de 2005. Disponible en: http://www.lanacion.com.ar/687989-el-agua-sube-turbia- 
ciados a explotaciones agropecuarias que funcionan bajo el modelo de producción señalado. Como respuesta, en algunos de los casos más graves se han iniciado procesos penales contra productores agropecuarios y sus contratistas ${ }^{13}$.

Sin perjuicio de las sanciones que le puedan caber a quienes realizan o intervienen directamente en las actividades contaminantes, y dado que uno de los rasgos típicos de la nueva lógica productiva es el del desdoblamiento entre la propiedad de la tierra y su explotación, el presente trabajo se concentra en analizar la eventual responsabilidad civil de los arrendadores ante daños ambientales indirectos ocasionados por sus arrendatarios, a la luz del bloque normativo compuesto por la Constitución Nacional, la leyes especiales y el nuevo Código Civil y Comercial de la Nación del año 2015 (CCCN $)^{14}$.

Para iniciar la tarea, el primer paso será revisar las notas sobresalientes del contrato de arrendamiento, que es el instrumento jurídico utilizado con mayor frecuencia para la transferencia del uso y goce de la tierra bajo este esquema productivo ${ }^{15}$, atendiendo especialmente a las disposiciones que regulan la relación entre partes y de estas con los terceros, si las hubiera.

en-junin. Durmiendo con el pesticida, Diario Página 12, 27 de marzo de 2015. Disponible en: http://www.pagina12.com.ar/diario/sociedad/3-269076-2015-03-27.html. Darío ArAnda, La salud cercada de Avia Terai, Diario Página 12, 20 de mayo de 2013. Disponible en: http:// www.pagina12.com.ar/diario/sociedad/3-220393-2013-05-20.html. LuCAs VIANO, Fumigadores cordobeses tienen la salud alterada, Diario La Voz de Córdoba, 10 de junio de 2015. Disponible en: http://www.lavoz.com.ar/ciudadanos/fumigadores-cordobeses-tienen-la-salud-alterada, entre muchos otros artículos periodísticos.

13 Carla Perelló, Al banquillo por rociar con glifosato, Diario Página 12, 3 de diciembre de 2012), Disponible en: http://www.pagina12.com.ar/diario/sociedad/3-209077-2012-12-03.html

14 Argentina, Código Civil y Comercial de la Nación argentina, Ley Nacional 26.994, 1 de octubre de 2014. Disponible en: http://www.infoleg.gob.ar/infolegInternet/anexos/235000-239999/235975/norma.htm

15 Según el Censo Nacional Agropecuario de 2002, más de 45.000 explotaciones producían bajo régimen de arrendamiento total o parcial de la tierra. Argentina, Instituto Nacional de Estadísticas y Censos, INDEC, Censo Nacional Agropecuario 2002. Disponible en: http:// www.indec.mecon.gov.ar/agropecuario/cna_defini2.asp 


\section{EL CONTRATO DE ARRENDAMIENTO RURAL EN ARGENTINA. SUS RASGOS DESTACADOS ${ }^{16}$}

Este contrato originariamente fue incluido dentro del Código Civil de $1869^{17}$ sin diferenciarlo de los arrendamientos urbanos, situación comprensible si se tiene en cuenta que para entonces el inmenso territorio argentino estaba apenas poblado y la figura del colono o arrendatario no tenía gran relevancia social o económica ${ }^{18}$.

Las fuertes corrientes inmigratorias, promovidas por las facilidades que ofrecía la Ley de Inmigración y Colonización 817 de 1876 (conocida como "Ley Avellaneda"), la creciente tecnificación del campo y el incremento del comercio internacional provocaron enormes cambios de contexto, que tornaron inadecuada la escasa normativa sobre la materia prevista en el Código Civil original.

Estas falencias desencadenaron importantes conflictos, como la célebre huelga denominada "Grito de Alcorta"19 el 25 de junio de 1912, determinante en la sanción de la primera ley especial de arrendamiento de predios rústicos de 1921 (Ley 11.170), que luego fue reemplazada en 1932 por la ley 11.627, ambas incorporadas como normativa complementaria del Código Civil.

La situación llegó a un punto crítico luego de finalizada la Segunda Guerra Mundial, debido a la crisis provocada por la pronunciada baja de los productos agrícolas y por los sistemáticos abusos contractuales a los que eran sometidos los arrendatarios, en su inmensa mayoría colonos inmigrantes.

En este contexto, se sancionó en 1948 la Ley de Arrendamientos Rurales y Aparcerías o Ley 13.246 (LAR), que continúa actualmente vigente. Si bien recogía muchos principios ya esbozados en las primeras normas, a diferencia de sus antecesoras, se apartó

16 La descripción del instrumento efectuada en esta sección refleja la literatura tradicional, y deja de lado los aspectos menos relevantes para el objeto en estudio, como la cuestión del plazo, las vinculaciones accidentales o de muy corta relación y las relaciones de aparcería.

17 Argentina, Código Civil, Ley 340, 25 de septiembre de 1869. Disponible en: http://servicios. infoleg.gob.ar/infolegInternet/verNorma.do?id=109481

18 Luis María Rezzónico, Intervención del Estado en la legislación rural, 10 (Librería Jurídica de Valerio Abeledo, Buenos Aires, 1951).

19 "Este Grito de Alcorta dio inicio al primer paro general para conseguir mejores condiciones en el arrendamiento de las tierras agrícolas en la República Argentina". GABRIELA DALLA Corte-Caballero, Marta Robotti y el Grito de Alcorta: Testimonios orales, historias vividas y agitación agraria, 17 Aljaba, 75-94 (2013). Disponible en: http://www.scielo.org.ar/scielo. php?pid=S1669-57042013000100005\&script $=$ sci_arttext 
del régimen civil estructurado originariamente sobre la base del principio de la autonomía de la voluntad, y se inspiró fundamentalmente en la tutela de la producción y en el cuidado de la familia agraria $^{20}$. La hasta entonces imperante concepción clásica del dominio fue reemplazada por una visión más tuitiva del recurso que reconocía las funciones preeminentemente sociales y productivas de la tierra agrícola por encima de las individuales, al establecer normas de carácter indisponible por la voluntad de las partes e imponer limitaciones al ejercicio del derecho de propiedad nunca antes reconocidas respecto a este tipo de bienes ${ }^{21}$.

Así, el carácter de orden público de esta norma surge explícito en el artículo 1 cuando establece: "La presente ley será aplicable a todo contrato, cualquiera sea la denominación que las partes le hayan asignado y sus distintas modalidades, siempre que conserve el carácter substancial de las prestaciones correlativas, conforme a sus preceptos, y su finalidad agroeconómica. Los preceptos de esta ley son de orden público, irrenunciables sus beneficios e insanablemente nulos y carentes de todo valor cualesquiera cláusulas o pactos en contrario o actos realizados en fraude a la misma".

Respecto a los caracteres del contrato, sabemos que - como el clásico contrato de arrendamiento - es consensual, de cambio, bilateral, conmutativo, formal y de tracto sucesivo.

El artículo 2 estipula que habrá contrato de arrendamiento rural cuando "una de las partes se obligue a conceder el uso y goce de un predio, ubicado fuera de la planta urbana de las ciudades o pueblos, con destino a la explotación agropecuaria en cualesquiera de sus especializaciones y la otra a pagar por ese uso y goce de un precio en dinero". Es decir, además de los presupuestos que caracterizan el contrato civil de locación de cosas (artículo $1187 \mathrm{CCCN}$ ), deben concurrir los elementos que distinguen la especie: el contrato debe recaer sobre un fundo rústico (ubicado fuera de las ciudades o pueblos, concepto que luego es detallado en las reglamentaciones

20 Fernando P. Brebita \& Nancy L. Malanos, Derecho agrario, 371 (Astrea, Buenos Aires, 2011). Argentina, Ley Nacional 13.246, 8 de septiembre de 1948, de Arrendamiento y Aparcerías Rurales, modificada por Ley 22.298, 23 de septiembre de 1980. Disponible en: http://infoleg. mecon.gov.ar/infolegInternet/anexos/65000-69999/66159/texact.htm, http://servicios.infoleg. gob.ar/infolegInternet/anexos/65000-69999/66159/texact.htm

21 Con esta ley se inaugura la conformación de una materia especial y distinta respecto del derecho civil: se da nacimiento al derecho agrario argentino como rama autónoma, con objeto y prioridades diversas de aquel. 
locales) y debe estar destinado a la explotación agropecuaria en cualquiera de sus especializaciones ${ }^{22}$.

Corresponde enfatizar que la contraprestación por la cesión del uso y goce del predio rural debe consistir indefectiblemente en un precio cierto en dinero, de lo que surge que en caso de fijarse una contraprestación en frutos, estaremos en presencia de otro contrato (aparcería o mediería) y no de un arrendamiento. Este requisito no existía en las leyes anteriores, ni en las costumbres rurales y dista mucho de ser una exigencia uniforme en el derecho comparado ${ }^{23}$.

En este punto, la ley prohíbe que se fije como precio del arrendamiento: a) la entrega de determinada cantidad fija de frutos ("contrato a kilaje fijo"), b) convenir como retribución un porcentaje fijo en la distribución de los frutos o dinero, o c) un adicional a abonarse en dinero o especie y de acuerdo con la cotización o la cantidad de frutos obtenidos, o en trabajos ajenos a la explotación del predio arrendado (modalidad comúnmente denominada "contrato canadiense" $)^{24}$.

Es decir, si la contraprestación a cargo del arrendatario no se fija en dinero sino en un porcentaje del total de frutos obtenidos, el contrato sería de aparcería; y si se establece en una cantidad fija de frutos (contrato a kilaje fijo) la cláusula sería nula. Del mismo modo sería nulo si se fijase en una suma fija de dinero o frutos pero además se pactara un tanto más, calculado sobre la productividad de la cosecha o su cotización ${ }^{25}$.

En lo que atañe a los derechos y obligaciones de las partes, veremos las específicas del contrato de arrendamiento rural, a las que deben sumarse aquellas del régimen general de locación civil mientras sean compatibles y no hayan sido modificadas por el régimen especial.

22 Fernando P. Brebita \& Nancy L. Malanos, Derecho agrario, 382 (Astrea, Buenos Aires, 2011).

23 Fernando P. Brebita \& Nancy L. Malanos, Derecho agrario, 388 (Astrea, Buenos Aires, 2011).

24 Una crítica a la prohibición de convenir este tipo de cláusulas en: Eugenia L. Bustamante, Los contratos regulados en la Ley de Arrendamientos Rurales y Aparcerías: necesidad de una reforma para adaptar las figuras contractuales a la realidad de la producción agropecuaria argentina, 3 Revista Jurídica de la Patagonia (diciembre de 2014). Disponible en: http://ijeditores.com.ar/ pop.php?option $=$ articulo \&Hash $=4 \mathrm{f} 37 \mathrm{a} 69 \mathrm{e} 74070201102527 \mathrm{dad} 5 \mathrm{aefd} 0 \mathrm{c}$

25 Un sector de la doctrina agrarista flexibiliza la rigidez de la postura, al afirmar que el precio fijado en referencia a otra cosa cierta, siempre que pueda ser determinado en fecha posterior, sería válido. Luis A. Facciano, El precio en los contratos de arrendamiento rural, en Derecho agrario, 159-165, 165 (Luis A. Facciano \& Paola C. Amigoni, coords., Instituto de Derecho Agrario del Colegio de Abogados de Rosario, Rosario, 2004). 
El artículo 18 establece que son obligaciones del arrendatario, además de las establecidas en el Código Civil y Comercial: "a) dedicar el suelo a la explotación establecida en el contrato con sujeción a las leyes y reglamentos agrícolas y ganaderos. b) Mantener el predio libre de plagas y malezas si lo ocupó en esas condiciones y contribuir con el cincuenta por ciento $(50 \%)$ de los gastos que demande la lucha contra las mismas, si estas existieran al ser arrendado el campo. c) Conservar los edificios y demás mejoras del predio, los que deberán $[s i c]$ entregar al retirarse en las mismas condiciones en que los recibiera, salvo los deterioros ocasionados por el uso y la acción del tiempo".

La obligación central del arrendador es la de "d) Contribuir con el cincuenta por ciento $(50 \%)$ de los gastos que demande la lucha contra las malezas y plagas si el predio las tuviera al contratar", entre otras, como la que se refiere al sostenimiento de la educación rural.

La normativa agrega en su artículo 8 una prohibición referida a la modalidad de explotación del recurso tierra, que es el objeto del contrato de arrendamiento. En su versión actual, establece que "queda prohibida toda explotación irracional del suelo que origine su erosión o agotamiento, no obstante cualquier cláusula en contrario que contengan los contratos respectivos. En caso de violarse esta prohibición por parte del arrendatario, el arrendador podrá rescindir el contrato o solicitar judicialmente el cese de la actividad prohibida, pudiendo reclamar en ambos casos los daños y perjuicios ocasionados. Si la erosión o agotamiento sobrevinieren por caso fortuito o fuerza mayor, cualquiera de las partes podrá declarar rescindido el contrato". Esta redacción modifica la versión original del artículo, al suprimir la potestad de intervención con que gozaba el Estado en caso de explotación irracional, y circunscribir el remedio a las acciones que puedan y quieran o no intentar las partes ${ }^{26}$.

El artículo en estudio se integra con una exhaustiva reglamentación de la ley ${ }^{27}$, que incluso contempla la posibilidad del arrendador

26 Fernando P. Brebita \& Nancy L. Malanos, Derecho agrario, 444 (Astrea, Buenos Aires, 2011).

27 El decreto Reglamentario define los conceptos de erosión, degradación y agotamiento (artículo 16). En su artículo 17 dispone: "Cuando aún no se hubiere provocado erosión, degradación o agotamiento, pero existiere irracionalidad en la explotación capaz de originarlos, se podrá intentar la acción para obtener la racionalidad de la explotación, por cualquiera de las partes". Argentina, Decreto 8.330, Reglamentario de la Ley de arrendamientos y aparcerías rurales, 30 de septiembre de 1963. Disponible en: http://infoleg.mecon.gov.ar/infolegInternet/ anexos/170000-174999/174460/norma.htm, http://servicios.infoleg.gob.ar/infolegInternet/ 
de interponer acción judicial preventiva en caso de que exista una explotación irracional aunque aún no le haya provocado daños concretos, lo que permite anticiparse al perjuicio ${ }^{28}$.

Del análisis literal surge que el contrato de arrendamiento se limita a regular estrictamente la relación entre arrendador y arrendatario, y no brinda referencias expresas o directas sobre la eventual responsabilidad que uno de ellos puede tener en caso de que el otro dañe a un tercero.

Esta decisión legislativa difiere de la tomada en otros contratos más modernos que también implican constitución o transmisión de relaciones de poder sobre cosas, en los que se fijan pautas específicas de responsabilidad por daños frente a terceros como sucede en los casos del seguro del fiduciario y del tomador del leasing (artículos 1685 y 1243 del CCCN, respectivamente).

En consecuencia, para resolver la cuestión particular de la posible existencia de responsabilidad del arrendador en caso de que la explotación agrícola administrada por el arrendatario ocasione daño ambiental a terceros, debemos remitirnos al sistema general de responsabilidad y, en particular, a la normativa sobre responsabilidad por daño ambiental. A continuación, nos detendremos en ellos.

\section{DAÑ̃ Ambiental: CONCEPTO, CLASES Y REGÍMENES DE RESPONSABILIDAD}

La doctrina argentina distingue en materia ambiental dos tipos de daños: el daño ecológico o directo y el daño indirecto. El primero, reconocido como daño ambiental stricto sensu, es aquel que impacta sobre el ambiente y está constituido por cualquier tipo de degradación física, química o biológica relevante sobre él. Abarca el deterioro del entorno o hábitat, el menoscabo del paisaje, y el perjuicio al patrimonio cultural; revistiendo carácter de daño

anexos/170000-174999/174460/norma.htm

28 La Ley de Arrendamientos Rurales fue pionera en el tratamiento de un problema actual que se enmarca en la temática de la cuestión ambiental y el desarrollo sustentable. Efectivamente, recién la reforma constitucional de 1994 casi medio siglo más tarde incluyó el derecho a un ambiente sano, el principio de desarrollo sustentable, y la obligación de recomposición del daño causado, universalizando y resignificando de esta manera la obligación de no llevar adelante explotaciones irracionales (y por ende no sustentables). Asimismo, establece como obligación prioritaria la recomposición, sin perjuicio de las acciones por daños y perjuicios derivados de incumplimientos contractuales que pudiesen corresponder. 
colectivo $^{29}$. Por su parte, el daño indirecto es la afectación en el patrimonio o en la salud de una o varias personas, producido por medio de disfuncionalidades ambientale ${ }^{30}$, o en otras palabras, un "daño a la persona y sus bienes por alteración del ambiente" ${ }^{31} \mathrm{y}$, por ende, se concibe como un daño de carácter individual.

Como resalta María Eugenia di PAOla, el daño ambiental per se altera o destruye parcial o totalmente los ecosistemas y la calidad de vida de los seres vivos que lo componen, mientras que el daño a los individuos a través del ambiente comprende justamente al ambiente como medio para producir un menoscabo a las personas o sus bienes ${ }^{32}$. Sin embargo, es habitual que el daño directo y el indirecto se presenten de manera simultánea, lo que lleva a la doctrina a destacar el rasgo de bipolaridad o de doble cara como característico de la fisonomía del daño ambiental ${ }^{33}$.

Así quedan diferenciadas las dos categorías de daños que la doctrina discierne en materia ambiental que, si bien pueden presentarse conjunta o separadamente, son distinguibles a partir de los bienes jurídicos tutelados en uno y otro caso: en el daño ambiental directo, el bien protegido es el ambiente autónomamente, como bien público, ya sea este el "macrobien ambiente o microbienes ambientales de dominio público" 34 , vinculados a derechos de carácter difuso o colectivo; mientras que en el daño indirecto el bien tutelado es la salud de la persona o de los bienes que integran su patrimonio, dando lugar a la existencia de derechos individuales. La jurispru-

29 La Ley 25.675 define el daño ambiental propiamente dicho en su artículo 27 como "[...] toda alteración relevante que modifique negativamente el ambiente, sus recursos, el equilibrio de los ecosistemas, o los bienes o valores colectivos". Argentina, Ley Nacional 25.675, 6 de noviembre de 2002, Ley General del Ambiente, LGA. Disponible en: http://www.infoleg.gob. ar/infolegInternet/anexos/75000-79999/79980/norma.htm

30 Marcelo López-Alfonsín, Derecho ambiental, 244-245 (Astrea, Buenos Aires, 2012).

31 Juan Walsh \& Federico Preuss, El daño ambiental: la necesidad de nuevas instituciones jurídicas, Revista Jurisprudencia Argentina, JA, 1996-IV-962 (1996), citados en Néstor A. CAFFERATTA, Los daños al ambiente y su reparación, 2008 Revista de Derecho de Daños, Rubinzal-Culzoni, 3, 163-199 (2008).

32 María Eugenia Di Paola, Daño ambiental, comentario al artículo 41, en Constitución de la Nación Argentina y normas complementarias. Análisis doctrinal y jurisprudencial, Tomo 2, 218-231, 221 (Daniel A. Sabsay, dir., Pablo A. Manili, coord., Hammurabi, Buenos Aires, 2010).

33 Néstor A. Cafferatta, Los daños al ambiente y su reparación, 2008 Revista de Derecho de Daños, Rubinzal-Culzoni, 3, 163-199, 171 (2008).

34 Ricardo L. Lorenzetti, La protección jurídica del ambiente, Revista La Ley, E-1463 (1997). 
dencia argentina también ha adoptado esta distinción, sin perjuicio del reconocimiento de su íntima vinculación ${ }^{35}$.

Con base en esta clasificación se determinan cuáles son los regímenes que regulan cada tipo de daño, los que tendrán especiales implicaciones en materia de competencia del tribunal, vías procesales para interponer el reclamo, factores de atribución de responsabilidad y prescripción de los daños ${ }^{36}$.

Para el daño ambiental directo, son aplicables el artículo 41 de la Constitución Nacional, los Pactos Internacionales incorporados, la Ley General del Ambiente (LGA), el bloque de normas federales conocidas como "Presupuestos Mínimos Ambientales"37, y las nor-

35 Suprema Corte de Justicia de la Provincia de Buenos Aires, Fallo Almada, Hugo N. C. Copetro S. A. y otro; Irazu, Margarita contra Copetro S. A. y otro; Klaus, Juan J. contra Copetro S. A. y otro, 19 de mayo de 1998. Disponible en: http://wp.cedha.net/wp-content/uploads/2011/07/199805-19-almada-c.-copetro.pdf. Suprema Corte de Justicia de la Provincia de Buenos Aires, Fallo Sagarduy, Alberto Omar contra Copetro S.A., 17 de diciembre de 2008. Disponible en: http:// www.scba.gov.ar/falloscompl/SCBA/2008/12-17/c98377.doc. Corte Suprema de Justicia de la Nación, Mendoza, Beatriz Silvia y otros contra Estado Nacional y otros sobre daños y perjuicios (daños derivados de la contaminación ambiental del Río Matanza - Riachuelo), 8 de agosto de 2008. Disponible en: http://www.farn.org.ar/riachuelo/documentos/fallo_riachuelo080708. pdf

36 Jorge Mosset-Iturraspe, El daño ambiental y los alcances del mandato judicial, Revista La Ley Buenos Aires, 1996-43 (1996). Mariana Catalano, Reparación de los daños individuales emergentes de la contaminación, 11 Revista de Responsabilidad Civil y Seguros: publicación mensual de doctrina, jurisprudencia y legislación, La Ley, 3, 55-67 (2009). Disponible en: AR/ DOC/1070/2009

37 Compuesto por varias Leyes Nacionales. Argentina, Ley Nacional 24.051 o Ley de Residuos Peligrosos, 17 de diciembre de 1991. Disponible en: http://servicios.infoleg.gob.ar/infolegInternet/anexos/0-4999/450/texact.htm. Argentina, Ley Nacional 25.612 o Ley de Gestión Integral de Residuos Industriales y de Actividades de Servicios, 3 de julio de 2002. Disponible en: http:// servicios.infoleg.gob.ar/infolegInternet/anexos/75000-79999/76349/norma.htm. Argentina, Ley Nacional 25.670 o Ley de Presupuestos Mínimos para la Gestión y Eliminación de los PCBs, 23 de octubre de 2002. Disponible en: http://servicios.infoleg.gob.ar/infolegInternet/ anexos/75000-79999/79677/norma.htm. Argentina, Ley Nacional 25.688 o Ley de Gestión Ambiental de Aguas, 28 de noviembre de 2002. Disponible en: http://servicios.infoleg.gob. ar/infolegInternet/anexos/80000-84999/81032/norma.htm. Argentina, Ley Nacional 25.831 o Ley de Libre acceso a la Información Pública, 26 de noviembre de 2003. Disponible en: http:// servicios.infoleg.gob.ar/infolegInternet/anexos/90000-94999/91548/norma.htm. Argentina, Ley Nacional 25.916 o Ley de Gestión de Residuos Domiciliarios, 4 de agosto de 2004. Disponible en: http://servicios.infoleg.gob.ar/infolegInternet/anexos/95000-99999/98327/norma. htm. Argentina, Ley Nacional 26.331, o Ley de Protección Ambiental de Bosques Nativos, 28 de noviembre de 2007. Disponible en: http://servicios.infoleg.gob.ar/infolegInternet/anexos/135000-139999/136125/norma.htm. Argentina, Ley Nacional 26.562 o Ley de protección ambiental para el control de actividades de quema, 18 de noviembre de 2009. Disponible en: http://servicios.infoleg.gob.ar/infolegInternet/anexos/160000-164999/161547/norma.htm. Argentina, Ley Nacional 26.639 o Ley de Preservación de los Glaciares y del Ambiente Periglacial, 30 de septiembre de 2010. Disponible en: http://servicios.infoleg.gob.ar/infolegInternet/ anexos/170000-174999/174117/norma.htm 
mas provinciales y municipales correspondientes a la jurisdicción de su acaecimiento o posible concurrencia.

A su vez, las normas para los supuestos de daño indirecto, que comúnmente se denominan "daños personales, patrimoniales o económicos" ${ }^{\prime 3}$, son las de responsabilidad del derecho civil ${ }^{39}$, siempre en consonancia con la Constitución Nacional y la LGA. En el CCCN se sitúan en los artículos 1749 y siguientes, para los casos de responsabilidad directa, y en los artículos 1757 y siguientes, para los de responsabilidad derivada de actividades riesgosas ${ }^{40}$.

Con el fin de delimitar el verdadero sentido y alcance de las normas regulatorias sobre esta última clase de responsabilidad resulta indispensable previamente especificar cuáles son los criterios interpretativos promovidos por la legislación sancionada recientemente (CCCN), que ayudarán a identificar la normativa aplicable para la resolución de estos casos.

\section{LAS PAUTAS DE INTERPRETACIÓN EN EL Código CIVIL Y COMERCIAL DE LA NACIÓN}

El artículo 2 del nuevo CCCN establece expresamente la necesidad de que en la interpretación del derecho se conjugue el texto expreso de la norma, con su finalidad, las leyes análogas, los tratados sobre derechos humanos y los principios y valores jurídicos, "de modo coherente con todo el ordenamiento".

En palabras de la doctrina, "el Código Civil y Comercial [...] pretende ser el factor de integración del conjunto de los microsistemas del derecho privado. Dicho de otro modo, las fuentes dialogan: las leyes especiales, los microsistemas, no existen en el aislamiento, en

38 Marcelo López-Alfonsín, Derecho ambiental, 247 (Astrea, Buenos Aires, 2012).

39 María Eugenia Di Paola, Daño ambiental, comentario al artículo 41, en Constitución de la Nación Argentina y normas complementarias. Análisis doctrinal y jurisprudencial, Tomo 2, 218-231, 221 (Daniel A. Sabsay, dir., Pablo A. Manili, coord., Hammurabi, Buenos Aires, 2010).

40 Para profundizar en la materia, Fernando Sagarna, Responsabilidad civil directa y por el hecho de terceros. En el nuevo Código Civil y Comercial de la Nación, en Suplemento Especial Nuevo Código Civil y Comercial, Revista La Ley (17 de noviembre de 2014). Ramón D. PizArro, Responsabilidad civil por actividades riesgosas o peligrosas en el nuevo Código, 2015-D Revista La Ley (12 de agosto de 2015). Jorge Mario Galdós, Riesgo creado y actividad riesgosa en el Proyecto 2012 de Código Civil y Comercial de la Nación, 3 Revista Derecho de Daños de La Ley (2012). Argentina, Código Civil y Comercial de la Nación argentina, Ley Nacional 26.994, 1 de octubre de 2014. Disponible en: http://www.infoleg.gob.ar/infolegInternet/anexos/ 235000-239999/235975/norma.htm 
el vacío, sin interrelación alguna; al contrario, sin perjuicio de sus reglas específicas, pueden acudir al $\mathrm{CCyC}$ como instrumento de integración al sistema"41.

El artículo citado consagra el mandato de perseguir una integración armónica del sistema jurídico, teniendo en consideración en todo momento las normas de jerarquía superior y las leyes especiales. Esta búsqueda exige repensar permanentemente los derechos y obligaciones de los sujetos, los que irán cambiando inexorablemente a medida que se introduzcan innovaciones al ordenamiento vía incorporación de tratados de derechos humanos, leyes especiales o, simplemente, por medio de la reinterpretación de estas fuentes, y a medida que las nuevas realidades tornen obsoletas las viejas interpretaciones ${ }^{42}$.

Del reconocimiento de que la sanción del $\mathrm{CCCN}$ ha dado impulso a un nuevo paradigma interpretativo, se sigue que las acotadas lecturas previas sobre el régimen del contrato de arrendamiento se han vuelto obsoletas. Por ello, a los fines de responder el interrogante acerca de la eventual responsabilidad ambiental de arrendador, se hace necesario formular una relectura de los derechos y obligaciones de los sujetos intervinientes y en especial de sus deberes en materia ambiental.

41 Aída Kemelmajer de Carlucci, Prólogo, en Código Civil y Comercial de la Nación comentado, Tomo I, xv-xix, xv, xvi (Marisa Herrera, Gustavo Caramelo \& Sebastián Picasso, dirs., Infojus, Buenos Aires, 2015). Disponible en: http://www.saij.gob.ar/docs-f/codigo-comentado/ CCyC_Comentado_Tomo_I\%20(arts.\%201\%20a\%20400).pdf. Según esta autora, la doctrina debe ser el principal instrumento para llevar adelante el diálogo de fuentes.

42 "El Código Civil y Comercial de la Nación inaugura su Título Preliminar refiriendo a los 'casos' que este Código rige. Un 'caso', como tal, no se entiende como un suceso histórico en su dimensión puramente fáctica; por el contrario, para el Derecho se trata, esencialmente, de un acontecimiento problemático que plantea la cuestión - muchas veces ardua- acerca de cómo responder a él en términos jurídicos. Las dificultades en la resolución de algunos de estos "casos" (hard cases) en una sociedad cada vez más compleja exigen generar continuas reconstrucciones interpretativas del ordenamiento vigente" (el énfasis es propio). AídA KeMELMAJER de Carlucci, Silvia Fernández \& Marisa Herrera, Bases para una relectura de la restricción a la capacidad civil en el nuevo Código, 1 Revista La Ley, 2015-D (2015). 


\section{REINTERPRETACIÓN DE LA PROHIBICIÓN DE EXPLOTACIÓN IRRACIONAL (ART. 8 DE LA LAR)}

\section{La consagración constitucional del principio de Desarrollo Sus-} tentable ${ }^{43}$ producida en 1994 es de fundamental importancia para el derecho agrario en general y para los contratos de explotación agraria en particular. Es precisamente el desarrollo sustentable el nexo o principio directivo que relaciona el derecho ambiental y la actividad agrícola ${ }^{44}$, en atención a que esta se lleva a cabo esencialmente mediante el uso de los recursos naturales y es una de sus principales fuentes de contaminación ${ }^{45}$.

A partir de este hito, el sistema jurídico argentino ha avanzado notablemente en la consolidación del derecho ambiental, que al constituirse en una disciplina legal de origen constitucional y de

43 Fue incorporado en el artículo 41, párrafo 1 de la Constitución Nacional, que textualmente dice: "Todos los habitantes gozan del derecho a un ambiente sano, equilibrado, apto para el desarrollo humano y para que las actividades productivas satisfagan las necesidades presentes sin comprometer las de las generaciones futuras; y tienen el deber de preservarlo (...)”. Argentina, Constitución de la Nación argentina, Ley 24.430, ordénase la publicación del texto oficial de la Constitución Nacional (sancionada en 1853 con las reformas de los años 1860, 1866, 1898, 1957 y 1994), 22 de agosto de 1994. Disponible en: http://www.infoleg.gob. ar/?page_id=63, http://servicios.infoleg.gob.ar/infolegInternet/anexos/0-4999/804/norma.htm

44 El principio del desarrollo sustentable indica a la agricultura que lleve adelante su actividad de tal manera que satisfaga las necesidades presentes, pero sin comprometer las de las generaciones futuras, que aplique una explotación que sea sustentable en el tiempo, es decir, que produzca conservando. Adolfo A. Coscia, Agricultura sostenible, 11 (Hemisferio Sur, Buenos Aires, 1993).

45 Según un informe de la FAO, "La agricultura representa la mayor proporción de uso de la tierra por el hombre. Solo los pastos y los cultivos ocupaban el 37 por ciento de la superficie de tierras de labranza del mundo en 1999. Casi dos terceras partes del agua utilizada por el hombre se destina a la agricultura (...) La producción agropecuaria tiene unos profundos efectos en el medio ambiente en conjunto. Son la principal fuente de contaminación del agua por nitratos, fosfatos y plaguicidas. También son la mayor fuente antropogénica de gases responsables del efecto invernadero, metano y óxido nitroso, y contribuyen en gran medida a otros tipos de contaminación del aire y del agua. Los métodos agrícolas, forestales y pesqueros y su alcance son las principales causas de la pérdida de biodiversidad del mundo. Los costos externos globales de los tres sectores pueden ser considerables. La agricultura afecta también a la base de su propio futuro a través de la degradación de la tierra, la salinización, el exceso de extracción de agua y la reducción de la diversidad genética agropecuaria” (...). Organización de las Naciones Unidas para la Agricultura y la Alimentación, FAO, Informe Técnico del Departamento de Desarrollo Económico y Social, Agricultura Mundial: hacia los años 2015/2030. Informe Resumido (Organización de las Naciones Unidas para la Agricultura y la Alimentación, FAO, Roma, 2002). Disponible en: http://www.fao.org/docrep/004/y3557s/ y3557s00.htm 
carácter transversal ${ }^{46}$ adquiere omnipresencia y relevancia preponderante.

En este sendero evolutivo también ocupan un lugar destacado la Ley General del Ambiente de $2002^{47}$ y el nuevo Código Civil y Comercial vigente desde el 1 de agosto de 2015, que modifican profundamente el sistema de derecho privado argentino, estableciendo este último que el ejercicio de los derechos individuales sobre los bienes debe ser compatible con los derechos de incidencia colectiva, y no puede afectar el funcionamiento ni la sustentabilidad de los ecosistemas, de la flora, la fauna, la biodiversidad y el agua (artículo $240 \mathrm{CCCN}$ ). El mismo cuerpo normativo dispone que la ley no ampara el ejercicio abusivo de los derechos individuales cuando puedan afectar el ambiente y los derechos de incidencia colectiva en general (artículo $14 \mathrm{CCCN}$ ) ${ }^{48}$. Desde la reforma, "la correcta manera de "leer" toda la estructura de ejercicio de derechos en relación con los bienes establecidos en el Código, es con la guía impuesta por los artículos 14, 240 y 241. Este es el prisma y el patrón con que debe observarse el resto del articulado" $"$.

Tal como hemos indicado anteriormente, estos cambios trascendentales obligan a releer en clave moderna la antigua normativa en estudio y nos valemos para ello de las pautas interpretativas provistas por la nueva legislación civil (artículo $2 \mathrm{CCCN}$ ).

Para acometer esta tarea será esencial comprender la evolución protagonizada por el artículo 8 de la LAR. Históricamente, este artículo fue entendido como circunscripto a la relación arrendadorarrendatario, y fue considerado en esencia una norma que otorgaba

46 Sobre el carácter trasversal del derecho ambiental: HoRAcio Allende-Rubino, La transversalidad del derecho ambiental, 7 Revista UNR Ambiental, Revista del Comité Universitario de Política Ambiental de la Universidad Nacional de Rosario, Laborde, Rosario (2006). Disponible en: http://docplayer.es/12876299-La-transversalidad-del-derecho-ambiental.html

47 Argentina, Ley Nacional 25.675, Ley General del Ambiente, 6 de noviembre de 2002. Disponible en: http://www.infoleg.gob.ar/infolegInternet/anexos/75000-79999/79980/norma.htm

48 "Se introduce por este medio un punto concreto de conexión entre el derecho privado positivo y la noción socioeconómica y ambiental de sustentabilidad, buscando encaminar el ejercicio del derecho hacia la concreción del derecho humano a un medio ambiente sano". MARIANA Blengio-Valdés, Derecho humano a un medio ambiente sano, II Revista de Derecho de la Universidad de Montevideo, 4, 5-17 (2003). Disponible en: http://revistaderecho.um.edu.uy/ wp-content/uploads/2012/10/DERECHO-4.pdf, http://revistaderecho.um.edu.uy/wp-content/ uploads/2012/12/Blengio-Derecho-humano-a-un-medio-ambiente-sano.pdf

49 Guillermo H. Marchesi, Límites al dominio y protección ambiental: la correcta manera de leer, 3 Diario Ambiental, 77 (30 de julio de 2015). Disponible en: https://dpicuantico.com/sitio/ wp-content/uploads/2015/07/Ambiental-Doctrina-2015-07-30.pdf_. 
una serie de facultades al arrendador para el supuesto de explotación irracional por parte del arrendatario. Resultaba importante para regular las relaciones entre partes, aunque inaplicable si los terceros perjudicados por la actividad contaminante del arrendatario pretendían reclamar cualquier tipo de resarcimiento al arrendador.

En consecuencia, cuando la explotación irracional en un inmueble arrendado generaba contaminación ambiental y afectaba a terceros, este arrendatario tradicionalmente quedaba bajo la órbita de la responsabilidad extracontractual, ya sea bajo factores de atribución subjetivos (culpa o dolo) u objetivos. El propietario-arrendador, en cambio, era percibido como una persona no vinculada con actividades productivas y que no tenía deberes de cuidado ni mayores responsabilidades ambientales frente a terceros; era un sujeto ajeno a la actividad desplegada por su arrendatario, únicamente se limitaba a ceder en uso y goce un bien propio, y por ello no podía ser llevado a los tribunales cuando la conducta del arrendatario contaminaba y perjudicaba a terceros.

Bajo el nuevo escenario, el artículo 8 de la LAR debe ser resignificado, actualizándolo a las realidades productivas actuales, y armonizándolo con los derechos y garantías constitucionales imperantes y con los modernos criterios de responsabilidad civil; para esta tarea, recurriremos al bloque normativo integrado por la Constitución Nacional, la Ley General del Ambiente y el Código Civil y Comercial de la Nación.

El objetivo original que inspiró la prohibición del artículo 8 fue primordialmente el cuidado del recurso tierra no como un elemento constitutivo del medioambiente, sino como recurso esencialmente económico o productivo $\mathrm{y}$, por tanto, valioso como generador de riqueza patrimonial. Esta perspectiva de la tierra como un "mero" medio de producción era afín a la concepción antropocéntrica y productivista que dominaba la época de la sanción de la ley de arrendamientos.

Una interpretación moderna de la prohibición de explotación irracional prevista en el artículo 8 de la LAR acorde con las modificaciones producidas en el marco normativo general, necesariamente debe revisar su contenido, el que ahora no puede consistir solamente en la interdicción de una conducta depredadora del recurso (contenido negativo) sino que debe — además — incorporar 
la obligación de explotar el suelo de manera sustentable (contenido positivo). Así lo señala Germán BidART-CAmpos, al destacar que el artículo 41 de la $\mathrm{CN}$ adjudica a todos los habitantes el deber jurídico de preservar el ambiente sano, deber que es exigible a cada persona y que convierte a todos en "una especie de agentes públicos del cuidado ambiental" $" 50$.

A partir de este giro copernicano del sistema jurídico, ya no parece válido sostener que el propietario-arrendador es el único o el principal interesado en hacer cumplir la prohibición de explotación irracional con miras a resguardar su patrimonio, sino que, situada por encima de él, es la sociedad toda la que tiene el legítimo interés de vivir en un ambiente sano y equilibrado y de que el desarrollo se produzca en forma sustentable.

En la misma dirección, la LGA, que es la ley especial en la materia, enumera como uno de los instrumentos de política ambiental el "sistema de control sobre el desarrollo de actividades antrópicas" (artículo 8 inciso 3). Por tanto, las regulaciones que imponen deberes de tutela ambiental y asignan responsabilidades en caso de producción de daños forman parte del sistema de control sobre actividades antrópicas y deben ser reputadas como instrumentos de política ambiental. De ello se desprende que resulta acertado calificar el artículo 8 de la LAR como una norma que integra o que debe funcionar en sintonía con la política ambiental nacional, toda vez que cumple una función directa en el control de una actividad antrópica como la explotación rural en el marco de un contrato de arrendamiento.

Además, la LGA en su artículo 4 establece que la interpretación de toda norma mediante la cual se ejecute la política ambiental queda sujeta al cumplimiento de una serie de principios, entre los que está el principio de prevención que es tomado directamente de la Constitución Nacional.

La doctrina ambientalista explica que "la Constitución Nacional, consagra en el artículo 41, el derecho al ambiente sano, equilibrado, apto para el desarrollo humano [...], y el desarrollo sustentable. Pero también, establece el 'deber de preservarlo', lo que se condice con los principios de política ambiental, de prevención y precau-

50 Germán Bidart-Campos, Manual de la Constitución Reformada, Tomo II, 86 (Ediar, Buenos Aires, 2010). 
ción, contenidos en el artículo 4 y 5 de la Ley 25.675 General del Ambiente. Dichos principios obligan al operador jurídico —el juez, la autoridad competente o de aplicación de la normativa ambiental一, metodológicamente, a priorizar el análisis, en la etapa previa al daño (predaño), operando sobre las causas y las fuentes de los problemas ambientales, tratando de impedir la consumación del daño ambiental"s51.

Este precepto constitucional, plasmado en el principio de prevención del artículo 4 de la LGA, necesariamente debe ser tenido en cuenta al interpretar la normativa del CCCN que posea injerencia clara o que directamente forme parte de la política ambiental.

Sumado a ello, la nueva función preventiva del sistema de responsabilidad general adoptado por el CCCN (art. 1710 y siguientes) se complementa armónicamente con el análisis efectuado de la ley especial. Sobre este tema, CAFFERATTA remarca que "el ingreso del principio de prevención al Código Civil y Comercial fortalece la postura de defensa del ambiente. Aunque hace tiempo se sabe en la doctrina que el Derecho de Daños incluye además de la resarcitoria o indemnizatoria, una función preventiva y disuasiva, es valioso que expresamente se establezca esta regla de funcionalidad del instituto de la responsabilidad civil, en todas sus variantes" 52 .

En este sentido, la interpretación efectuada del artículo 8 de la LAR se adecúa mejor que la versión tradicional al principio de prevención del daño ambiental y a la función preventiva del nuevo sistema de responsabilidad del CCCN. Esta aseveración se fundamenta en que la incorporación del arrendador como responsable por daños ambientales indirectos ocasionados por el arrendatario genera incentivos para que una persona adicional (el arrendador) lleve adelante medidas de control sobre la explotación, aumentan-

51 Néstor A. CAfferatta, Derecho ambiental en el Código Civil y Comercial de la Nación, Revista La Ley, Suplemento Especial Nuevo Código Civil y Comercial (noviembre de 2014). Disponible en: http://www.nuevocodigocivil.com/wp-content/uploads/2015/02/Derecho-ambiental-en-elCodigo-Civil-y-Comercial-de-la-Nacion.-Por-Nestor-A-Cafferatta.pdf

52 Néstor A. Cafferatta, Derecho ambiental en el Código Civily Comercial de la Nación, Revista La Ley, Suplemento Especial Nuevo Código Civil y Comercial (noviembre de 2014). Disponible en: http://www.nuevocodigocivil.com/wp-content/uploads/2015/02/Derecho-ambiental-en-elCodigo-Civil-y-Comercial-de-la-Nacion.-Por-Nestor-A-Cafferatta.pdf. En sentido concordante, puede verse: PABLo LorenzetTi, Funciones de la responsabilidad civil y daño ambiental en el Proyecto de Código Civil y Comercial de la Nación de 2012, 15 Revista de responsabilidad civil y seguros: publicación mensual de doctrina, jurisprudencia y legislación, La Ley, 8, 5-21 (2013). 
do así las posibilidades de prevención de daños ambientales. Ello también incrementa las chances de reparación o recomposición en caso de que el daño se verifique, al agregar un patrimonio adicional sobre el cual perseguir el cobro de las indemnizaciones debidas.

Por estas razones, una relectura que armonice los preceptos constitucionales, la ley especial y el nuevo diseño en materia de responsabilidad civil debe concluir que el artículo 8 de la LAR se entiende como constitutivo de un deber jurídico de control que recae en cabeza del arrendador y no como mera facultad y que, por lo tanto, genera responsabilidad en caso de incumplimiento.

Ante la omisión o deficiente supervisión de su arrendatario, el arrendador quedará sujeto a las disposiciones de la responsabilidad civil directa (artículo $1749 \mathrm{CCCN})^{53}$. Explica la doctrina que "de acuerdo al hecho que genera el deber de reparar, suele clasificarse a la responsabilidad en directa e indirecta. Mientras que en este segundo caso se es responsable por el hecho de otro [...], en el primero se responde por el hecho propio: la obligación de reparar es impuesta a quien causó el daño por una acción u omisión suyas" ${ }^{54}$. El factor de atribución de responsabilidad es subjetivo (dolo o culpa $^{55}$, y las circunstancias eximentes o atenuantes del deber de reparar serán las previstas para este tipo de imputación (verbigracia: ruptura del nexo causal, el hecho de la víctima, el caso fortuito o fuerza mayor y el hecho de un tercero por quien no se deba responder - remarcando que el arrendatario no puede ser incluido en este último supuesto-).

Esta adjudicación de responsabilidades en materia ambiental al propietario de un inmueble en el que se realizan actividades productivas que pueden ocasionar daños a terceros - con inde-

53 Artículo $1749 \mathrm{CCCN}$ : "Sujetos responsables. Es responsable directo quien incumple una obligación u ocasiona un daño injustificado por acción u omisión". Argentina, Código Civil y Comercial de la Nación argentina, Ley Nacional 26.994, 1 de octubre de 2014. Disponible en: http://www.infoleg.gob.ar/infolegInternet/anexos/235000-239999/235975/norma.htm

54 Jorge Mario Galdós, Responsabilidad directa, en Código civil y comercial de la Nación comentado, 537-557, 538 (Miguel de Lorenzo \& Pablo Lorenzetti, coords., Rubinzal-Culzoni, Buenos Aires, 2015).

55 "Aunque el Código no lo diga expresamente, está claro que el factor de atribución aplicable en el caso que se está analizando no puede ser otro que el dolo o la culpa. Es que ninguna norma del Código [...] prevé un factor objetivo para los daños causados por el hecho propio, lo que toma aplicable el artículo 1721, a cuyo tenor en ausencia de normativa específica el factor de atribución es la culpa". Jorge Mario Galdós, Responsabilidad directa, en Código Civil y Comercial de la Nación comentado, 537-557, 542 (Miguel de Lorenzo \& Pablo Lorenzetti, coords., Rubinzal-Culzoni, Buenos Aires, 2015). 
pendencia de que tenga o no control directo de ellas-, cuenta con diversos antecedentes en Argentina, país donde variantes análogas están vigentes en la normativa ambiental provincial ${ }^{56}$. Estas son, posiblemente, las primeras reacciones legislativas que denotan la comprensión de que bajo el nuevo paradigma ambiental, la tierra abandona su mera función instrumental como fuente de extracción de riqueza para pasar a formar parte de un grupo de bienes que deben ser explotados bajo ciertos parámetros estrictos pues está en juego el interés general. Por esta razón, el rol de contralor del Estado debe ser acompañado por los individuos que estén en la mejor posición para asistirlo, como sucede con el propietario-arrendador en el caso bajo estudio.

56 Artículo 5 de la Ley 14.343. "De los responsables. Están obligados a recomponer los pasivos ambientales y/o sitios contaminados, los sujetos titulares de la actividad generadora del daño y/o los propietarios de los inmuebles, en el caso de que no se pueda ubicar al titular de la actividad [...]”. Argentina, Ley 14.343 de la Provincia de Buenos Aires, 23 de noviembre de 2011. Disponible en: http://www.gob.gba.gov.ar/legislacion/legislacion/l-14343.html. La constitucionalidad de este artículo ha sido cuestionada por algunos autores. Guillermo Malm-Green \& Ángeles Murgier, La nueva Ley de Pasivos Ambientales de la Provincia de Buenos Aires, 360 Revista La Ley Buenos Aires (mayo de 2012). Disponible en: http://thomsonreuterslatam. com/2012/07/18/doctrina-del-dia-la-nueva-ley-de-pasivos-ambientales-de-la-provincia-debuenos-aires/. En el mismo sentido, el Artículo 91 de la Ley 10.208 de la Provincia de Córdoba: "Los sujetos titulares de la actividad generadora del pasivo [ambiental] o los propietarios de los inmuebles — en el caso de que no se pueda ubicar al titular de la actividad-, están obligados a recomponer los pasivos ambientales o sitios contaminados. En caso de que no pudiere ser establecida la identidad o ante la imposibilidad de ubicarla físicamente, las responsabilidades recaen en el titular dominial del inmueble donde se originó el pasivo ambiental". Argentina, Ley 10.208 de la Provincia de Córdoba, 11 de junio de 2014. Disponible en: http://www.cba.gov.ar/ wp-content/4p96humuzp/2014/07/LEY-DE-POLITICA-AMBIENTAL-DE-LA-PCIA-10208. pdf. Ambas normas se refieren a recomposición de pasivos ambientales, cuya definición es comprensiva del daño colectivo o directo, pero no generan obligaciones de reparar daños indirectos. No obstante ello, y a pesar de que la imputación de responsabilidad al propietario es subsidiaria, producen una clara fractura con los antecedentes o posiciones tradicionales en la cuestión, y podrían interpretarse como evidencia ostensible de que está en curso un cambio de paradigma en materia de responsabilidad ambiental. 


\section{SÍNTESIS}

En los últimos años, se han producido cambios notables en el sistema jurídico argentino, que comenzaron con la reforma constitucional de 1994, continuaron con el dictado de importantes leyes ambientales (en especial, la LGA), y culminaron, al menos por el momento, con la reciente sanción del Código Civil y Comercial. Los textos que integran este bloque normativo han consagrado de manera expresa nuevos derechos y obligaciones y, adicionalmente, han impulsado un mecanismo de interpretación e integración normativa que compele a efectuar una relectura de todos los institutos jurídicos en clave moderna.

En un contexto en el que comienzan a multiplicarse los conflictos ambientales asociados a explotaciones rurales insustentables, el presente trabajo lleva adelante una tarea reinterpretativa de los derechos y obligaciones de las partes del contrato de arrendamiento y se enfoca particularmente en los deberes ambientales del arrendador.

Con base en los argumentos expuestos, sostenemos que el arrendador está sometido a un verdadero deber de control sobre las actividades que se desarrollan en su propiedad, aunque estas sean realizadas por un contratante a quien cedió el uso y goce del inmueble, y que en caso de incumplimiento de este deber y frente a daños ambientales sufridos por terceros, podrá ser tenido por responsable y obligado a costear las reparaciones correspondientes. 


\section{BIBLIOGRAFíA}

\section{Libros}

Barsky, Osvaldo \& Gelman, Jorge, Historia del agro argentino. Desde la Conquista hasta fines del siglo $X X\left(3^{\text {a }}\right.$ edición actualizada, Sudamericana, Buenos Aires, 2009).

Bidart-Campos, Germán, Manual de la Constitución Reformada, Tomo II (Ediar, Buenos Aires, 2010).

Brebbia, Fernando P. \& Malanos, Nancy L., Derecho agrario (Astrea, Buenos Aires, 2011).

Coscia, Adolfo A., Agricultura sostenible (Hemisferio Sur, Buenos Aires, 1993).

Gras, Carla \& Hernández, Valeria, coords., La Argentina rural. De la agricultura familiar a los agronegocios (Biblos, Buenos Aires, 2009).

Gras, Carla \& Hernández, Valeria, coords., El agro como negocio. Producción, sociedad $y$ territorios en la globalización (Biblos, Buenos Aires, 2013).

LóPez-Alfonsín, Marcelo, Derecho ambiental (Astrea, Buenos Aires, 2012).

Rezzónico, Luis M., Intervención del Estado en la legislación rural (Librería Jurídica de Valerio Abeledo, Buenos Aires, 1951).

SCheinkerman de Obschatko, Edith, El aporte del sector agroalimentario al crecimiento económico argentino 1965-2000 (Instituto Interamericano de Cooperación para la Agricultura, IICA, Buenos Aires, 2003). Disponible en: http://www.sidalc.net/ repdoc/A8548e/A8548e.pdf

Teubal, Miguel, Globalización y expansión agroindustrial. ¿Superación de la pobreza en América Latina? (Corregidor, Buenos Aires, 1995).

Teubal, Miguel \& Rodríguez, Jorge, Agro y alimentos en la globalización: una perspectiva crítica (La Colmena, Buenos Aires, 2002).

\section{Contribución en obras colectivas}

Bisang, Roberto; Anlló, Guillermo \& Campi, Mercedes, Capítulo 10, Organización del agro. La transición de un modelo de integración vertical a las redes de producción agrícola, en El crecimiento de la agricultura argentina. Medio siglo de logros y desafíos, 231-254 (Lucio G. Reca, Daniel Lema \& Carlos Flood, eds., Editorial Facultad Agronomía de la Universidad de Buenos Aires, UBA, Buenos Aires, 2010).

Díaz-Hermelo, Francisco \& Reca, Alejandro, Capitulo 9, Asociaciones Productivas (APs) en la Agricultura: una respuesta dinámica a fallas de mercado y al cambio tecnológico, en El crecimiento de la agricultura argentina. Medio siglo de logros y desafíos, 207-230 (Lucio G. Reca, Daniel Lema \& Carlos Flood, eds., Editorial Facultad Agronomía de la Universidad de Buenos Aires, UBA, Buenos Aires, 2010).

FACCiAno, Luis A., El precio en los contratos de arrendamiento rural, en Derecho agrario, 
159-165 (Luis A. Facciano \& Paola C. Amigoni, coords., Instituto de Derecho Agrario del Colegio de Abogados de Rosario, Rosario, 2004).

Galdós, Jorge Mario, Responsabilidad directa, en Código Civil y Comercial de la Nación comentado, 537-557 (Miguel de Lorenzo \& Pablo Lorenzetti, coords., RubinzalCulzoni, Buenos Aires, 2015).

Kemelmajer de Carlucci, Aída, Prólogo, en Código Civil y Comercial de la Nación comentado, Tomo I, xv-xix (Marisa Herrera, Gustavo Caramelo \& Sebastián Picasso, dirs., Infojus, Buenos Aires, 2015). Disponible en: http://www.saij.gob. ar/docs-f/codigo-comentado/CCyC_Comentado_Tomo_I $\% 20$ (arts.\%201\%20 $\mathrm{a} \% 20400) . p d f$

Paola, María Eugenia di, Daño ambiental, comentario al artículo 41, en Constitución de la Nación Argentina y normas complementarias. Análisis doctrinal y jurisprudencial, Tomo 2, 218-231 (Daniel A. Sabsay, dir., Pablo A. Manili, coord., Hammurabi, Buenos Aires, 2010).

\section{Revistas}

Allende-Rubino, Horacio, La transversalidad del derecho ambiental, 7 Revista UNR Ambiental, Revista del Comité Universitario de Política Ambiental de la Universidad Nacional de Rosario, Laborde, Rosario (2006). Disponible en: http:// docplayer.es/12876299-La-transversalidad-del-derecho-ambiental.html

Blengio-Valdés, Mariana, Derecho humano a un medio ambiente sano, II Revista de Derecho de la Universidad de Montevideo, 4, 5-17 (2003). Disponible en: http:// revistaderecho.um.edu.uy/wp-content/uploads/2012/10/DERECHO-4.pdf, http://revistaderecho.um.edu.uy/wp-content/uploads/2012/12/Blengio-Derechohumano-a-un-medio-ambiente-sano.pdf

Bustamante, Eugenia L., Los contratos regulados en la Ley de Arrendamientos Rurales y Aparcerías: necesidad de una reforma para adaptar las figuras contractuales a la realidad de la producción agropecuaria argentina, 3 Revista Jurídica de la Patagonia (diciembre de 2014). Disponible en: http://ijeditores.com.ar/pop.php? option $=$ articulo\&Hash $=4 \mathrm{f} 37 \mathrm{a} 69 \mathrm{e} 74070201102527 \mathrm{dad} 5 \mathrm{aefd} 0 \mathrm{c}$

Cafferatta, Néstor A., Derecho ambiental en el Código Civil y Comercial de la Nación, Revista La Ley, Suplemento Especial Nuevo Código Civily Comercial (noviembre de 2014). Disponible en: http://www.nuevocodigocivil.com/wp-content/ uploads/2015/02/Derecho-ambiental-en-el-Codigo-Civil-y-Comercial-de-laNacion.-Por-Nestor-A-Cafferatta.pdf

CAfFeratta, Néstor A., Los daños al ambiente y su reparación, 2008 Revista de Derecho de Daños, Rubinzal-Culzoni, 3, 163-199 (2008).

Catalano, Mariana, Reparación de los daños individuales emergentes de la contaminación, 11 Revista de Responsabilidad Civil y Seguros: publicación mensual de doctrina, jurisprudencia y legislación, La Ley, 3, 55-67 (2009).

Corte-Caballero, Gabriela dalla, Marta Robotti y el Grito de Alcorta: Testimonios orales, historias vividas y agitación agraria, 17 Aljaba, $75-94$ (2013). Disponible en: http://www.scielo.org.ar/scielo.php?pid=S1669-57042013000100005\&script=sci_ arttext 
Galdós, Jorge Mario, Riesgo creado y actividad riesgosa en el Proyecto 2012 de Código Civil y Comercial de la Nación, 3 Revista Derecho de Daños de La Ley (2012).

Gras, Carla, Los empresarios de la soja: cambios y continuidades en la fisonomía y composición interna de las empresas agropecuarias, 12 Mundo Agrario, 24 (2012). Disponible en: http://mundoagrario.unlp.edu.ar/article/view/v12n24a04/2142

Grobocopatel, Gustavo, Los agronegocios y la sustentabilidad en la economía del conocimiento, Suplemento Ambiental Revista La Ley (29 de abril de 2013). Disponible en: http://www.losgrobo.com.ar/comunicados/descargas/ suplemento_agro29042013.pdf

Grosso, Susana; Bellini, María Eva; Qüesta, Laura; Guibert, Martine; Lauxmann, Silvia \& Rotondi, Fabiana, Impactos de los "pools de siembra" en la estructura social agraria: Una aproximación a las transformaciones en los espacios centrales de la provincia de Santa Fe (Argentina), 6 Revista de Estudios Regionales y Mercado de Trabajo, 115-138 (2010). Disponible en: http://www.memoria.fahce.unlp.edu. ar/art_revistas/pr.4537/pr.4537.pdf

Kemelmajer de Carlucci, Aída; Fernández, Silvia \& Herrera, Marisa, Bases para una relectura de la restricción a la capacidad civil en el nuevo Código, 1 Revista La Ley, 2015-D (2015).

Lorenzetti, Pablo, Funciones de la responsabilidad civil y daño ambiental en el Proyecto de Código Civil y Comercial de la Nación de 2012, 15 Revista de responsabilidad civil y seguros: publicación mensual de doctrina, jurisprudencia y legislación, La Ley, 8, 5-21 (2013).

LorenzetTi, Ricardo L., La protección jurídica del ambiente, Revista La Ley, E-1463 (1997).

Malm-Green, Guillermo \& Murgier, Ángeles, La nueva Ley de Pasivos Ambientales de la Provincia de Buenos Aires, 360 Revista La Ley Buenos Aires (mayo de 2012). Disponible en: http://thomsonreuterslatam.com/2012/07/18/doctrina-del-dia-lanueva-ley-de-pasivos-ambientales-de-la-provincia-de-buenos-aires/

MarChesi, Guillermo H., Límites al dominio y protección ambiental: la correcta manera de leer, 3 Diario Ambiental, 77 (30 de julio de 2015). Disponible en: https://dpicuantico. com/sitio/wp-content/uploads/2015/07/Ambiental-Doctrina-2015-07-30.pdf

Mosset-Iturraspe, Jorge, El daño ambiental y los alcances del mandato judicial, Revista La Ley Buenos Aires, 1996-43 (1996).

Pizarro, Ramón D., Responsabilidad civil por actividades riesgosas o peligrosas en el nuevo Código, 2015-D Revista La Ley (12 de agosto de 2015).

SAgarna, Fernando, Responsabilidad civil directa y por el hecho de terceros. En el nuevo Código Civil y Comercial de la Nación, en Suplemento Especial Nuevo Código Civil y Comercial, Revista La Ley (17 de noviembre de 2014).

Walsh, JuAN \& Preuss, Federico, El daño ambiental: la necesidad de nuevas instituciones jurídicas, Revista Jurisprudencia Argentina, JA, 1996-IV-962 (1996). 


\section{Working paper}

Manciana, Eduardo; Trucco, Mario \& Piñeiro, Martín, Large-Scale Acquisition of Land Rights for Agricultural or Natural Resource-Based Use: Argentina, 1-84 (World Bank, Working Paper, 2009). Disponible en: http://papers.ssrn.com/sol3/ papers.cfm?abstract_id=1915343

\section{Normativa argentina}

Argentina, Código Civil, Ley 340, 25 de septiembre de 1869. Disponible en: http:// servicios.infoleg.gob.ar/infolegInternet/verNorma.do?id=109481

Argentina, Código Civil y Comercial de la Nación argentina, Ley Nacional 26.994, 1 de octubre de 2014. Disponible en: http://www.infoleg.gob.ar/infolegInternet/ anexos/235000-239999/235975/norma.htm

Argentina, Constitución de la Nación argentina, Ley 24.430, ordénase la publicación del texto oficial de la Constitución Nacional (sancionada en 1853 con las reformas de los años 1860, 1866, 1898, 1957 y 1994), 22 de agosto de 1994. Disponible en: http:// www.infoleg.gob.ar/?page_id=63, http://servicios.infoleg.gob.ar/infolegInternet/ anexos/0-4999/804/norma.htm

Argentina, Decreto 8.330, Reglamentario de la Ley de arrendamientos y aparcerías rurales, 30 de septiembre de 1963. Disponible en: http://infoleg.mecon.gov. ar/infolegInternet/anexos/170000-174999/174460/norma.htm, http://servicios. infoleg.gob.ar/infolegInternet/anexos/170000-174999/174460/norma.htm

Argentina, Ley 14.343 de la Provincia de Buenos Aires, 23 de noviembre de 2011. Disponible en: http://www.gob.gba.gov.ar/legislacion/legislacion/l-14343.html

Argentina, Ley 10.208 de la Provincia de Córdoba, 11 de junio de 2014. Disponible en: http://www.cba.gov.ar/wp-content/4p96humuzp/2014/07/LEY-DE-POLITICAAMBIENTAL-DE-LA-PCIA-10208.pdf

Argentina, Ley 817, Ley de Inmigración y Colonización, 6 de octubre de 1876.

Argentina, Ley 11.170, Ley de Arrendamientos Rurales, 28 de septiembre de 1921.

Argentina, Ley 11.627, Ley de Contratos de Arrendamientos Agrícolas, 28 de septiembre de 1932.

Argentina, Ley Nacional 13.246, Ley de Arrendamiento y Aparcerías Rurales, 8 de septiembre de 1948, modificada por Ley 22.298, 23 de septiembre de 1980. Disponible en: http://infoleg.mecon.gov.ar/infolegInternet/ anexos/65000-69999/66159/texact.htm, http://servicios.infoleg.gob.ar/ infolegInternet/anexos/65000-69999/66159/texact.htm

Argentina, Ley Nacional 24.051 o Ley de Residuos Peligrosos, 17 de diciembre de 1991. Disponible en: http://servicios.infoleg.gob.ar/infolegInternet/anexos/0-4999/450/ texact.htm

Argentina, Ley Nacional 25.612 o Ley de Gestión Integral de Residuos Industriales y de Actividades de Servicios, 3 de julio de 2002. Disponible en: http://servicios. infoleg.gob.ar/infolegInternet/anexos/75000-79999/76349/norma.htm 
Argentina, Ley Nacional 25.670 o Ley de Gestión y Eliminación de PCB, 23 de octubre de 2002. Disponible en: http://servicios.infoleg.gob.ar/infolegInternet/ anexos/75000-79999/79677/norma.htm

Argentina, Ley Nacional 25.675, Ley General del Ambiente, 6 de noviembre de 2002. Disponible en: http://www.infoleg.gob.ar/infolegInternet/ anexos/75000-79999/79980/norma.htm

Argentina, Ley Nacional 25.688 o Ley de Gestión Ambiental de Aguas, 28 de noviembre de 2002. Disponible en: http://servicios.infoleg.gob.ar/infolegInternet/ anexos/80000-84999/81032/norma.htm

Argentina, Ley Nacional 25.831 o Ley de Libre acceso a la Información Pública, 26 de noviembre de 2003. Disponible en: http://servicios.infoleg.gob.ar/infolegInternet/ anexos/90000-94999/91548/norma.htm

Argentina, Ley Nacional 25.916 o Ley de Presupuestos Mínimos para la Gestión de Residuos Domiciliarios, 4 de agosto de 2004. Disponible en: http://servicios. infoleg.gob.ar/infolegInternet/anexos/95000-99999/98327/norma.htm

Argentina, Ley Nacional 26.331 o Ley de Protección Ambiental de Bosques Nativos, 28 de noviembre de 2007. Disponible en: http://servicios.infoleg.gob.ar/ infolegInternet/anexos/135000-139999/136125/norma.htm

Argentina, Ley Nacional 26.562 o Ley de Actividades de quema en todo el Territorio Nacional, 18 de noviembre de 2009. Disponible en: http://servicios.infoleg.gob. ar/infolegInternet/anexos/160000-164999/161547/norma.htm

Argentina, Ley Nacional 26.639 o Ley de Preservación de los Glaciares y del Ambiente Periglacial, 30 de septiembre de 2010. Disponible en: http://servicios.infoleg.gob. ar/infolegInternet/anexos/170000-174999/174117/norma.htm

\section{Jurisprudencia argentina}

Corte Suprema de Justicia de la Nación, Mendoza, Beatriz Silvia y otros contra Estado Nacional y otros sobre daños y perjuicios (daños derivados de la contaminación ambiental del Río Matanza - Riachuelo), 8 de agosto de 2008. Disponible en: http://www.farn.org.ar/riachuelo/documentos/fallo_riachuelo080708.pdf

Suprema Corte de Justicia de la Provincia de Buenos Aires, Fallo Almada, Hugo N. C. Copetro S. A. y otro; Irazu, Margarita contra Copetro S. A. y otro; Klaus, Juan J. contra Copetro S. A. y otro, 19 de mayo de 1998. Disponible en: http://wp.cedha. net/wp-content/uploads/2011/07/1998-05-19-almada-c.-copetro.pdf

Suprema Corte de Justicia de la Provincia de Buenos Aires, Fallo Sagarduy, Alberto Omar contra Copetro S.A., 17 de diciembre de 2008. Disponible en: http://www. scba.gov.ar/falloscompl/SCBA/2008/12-17/c98377.doc 


\section{Documentos, informes, reportes}

Argentina, Instituto Nacional de Estadísticas y Censos, INDEC, Censo Nacional Agropecuario 2002. Disponible en: http://www.indec.mecon.gov.ar/agropecuario/ cna_defini2.asp

BISANG, RoBerto, El desarrollo agropecuario en las últimas décadas: ¿volver a creer?, en Crisis, recuperación y nuevos dilemas: la economía argentina 2002-2007, 187-260 (Bernardo P. Kosacoff, ed., Comisión Económica para América Latina y el Caribe, CEPAL, Buenos Aires, 2007). Disponible en: http://repositorio.cepal.org/ handle/11362/4237, http://repositorio.cepal.org/bitstream/handle/11362/28481/1/ S2007021_es.pdf

Organización de las Naciones Unidas para la Agricultura y la Alimentación, FAO, Informe Técnico del Departamento de Desarrollo Económico y Social, Agricultura Mundial: hacia los años 2015/2030. Informe Resumido (Organización de las Naciones Unidas para la Agricultura y la Alimentación, FAO, Roma, 2002). Disponible en: http://www.fao.org/docrep/004/y3557s/y3557s00.htm

Soto-Baquero, Fernando \& Gómez, Sergio, eds., Dinámicas del mercado de la tierra en América Latina y el Caribe: concentración y extranjerización (Organización de las Naciones Unidas para la Alimentación y la Agricultura, FAO, Roma, 2012). Disponible en: www.fao.org/docrep/019/i2547s/i2547s.pdf

\section{Medios de comunicación}

Aranda, Darío, La salud cercada de Avia Terai, Diario Página 12, 20 de mayo de 2013. Disponible en: http://www.pagina12.com.ar/diario/sociedad/3-220393-2013-05-20. html

Durmiendo con el pesticida, Diario Página 12, 27 de marzo de 2015. Disponible en: http:// www.pagina12.com.ar/diario/sociedad/3-269076-2015-03-27.html

Heguy, Silvina, Mal uso y falta de control: el drama de los chicos que crecen en pueblos fumigados, Diario Clarín, 6 de enero de 2013. Disponible en: http://www.clarin. com/zona/Mal-uso-falta-control_0_842315859.html

Perelló, Carla, Al banquillo por rociar con glifosato, Diario Página 12, 3 de diciembre de 2012), disponible en: http://www.pagina12.com.ar/diario/ sociedad/3-209077-2012-12-03.html

Verlichak, Carmen, El agua sube turbia en Junín, Diario La Nación, 19 de marzo de 2005. Disponible en: http://www.lanacion.com.ar/687989-el-agua-sube-turbia-en-junin

Viano, LuCas, Fumigadores cordobeses tienen la salud alterada, Diario La Voz de Córdoba, 10 de junio de 2015. Disponible en: http://www.lavoz.com.ar/ciudadanos/ fumigadores-cordobeses-tienen-la-salud-alterada 